\title{
Revisão sistemática sobre avaliação para identificação inicial de alunos com deficiência intelectual
}

\author{
Érika Rímoli Mota da Silva* \\ Maria da Piedade Resende da Costa**
}

\section{Resumo}

Um dos serviços para atendimento dos alunos público alvo da educação especial, entre eles os alunos com deficiência intelectual (DI), são os Atendimentos Educacionais Especializados. Grande parte desses alunos é identificada num primeiro momento pelos professores (da sala comum ou da sala de recursos). A partir disso, surgiram algumas questóes, as quais, para serem respondidas, a presente pesquisa teve por objetivo investigar as formas de identificação de alunos com DI, por meio de revisão sistemática de publicaçóes científicas encontradas em bases de dados online no período de 2010 a 2017. A referida revisão foi realizada das publicaçóes pertinentes, selecionadas de acordo com resultados provenientes de 10 combinaçóes entre sete termos de pesquisa. A busca se deu nas bases de dados Lilacs e Portal de Periódicos da Capes. Após sistematização e análise do conteúdo das publicaçôes e extração de informaçóes referentes à forma de identificaçâo deste público, realizou-se a categorização dos textos de acordo com as temáticas dos estudos encontrados. Constatou-se que as pesquisas não apresentam formas de avaliaçáo objetivas, relatando-as superficialmente, mencionando em sua maioria critérios como os estabelecidos pela Associação Americana sobre Deficiência Intelectual e Desenvolvimento, questáo que não ocorre apenas no Brasil, mas também em outros países da América Latina, segundo apontam os estudos realizados. Tendo em vista a escassez de resultados, ressalta-se a importância da realização de pesquisas que enfoquem a sistematização, padronização e divulgação das formas de avaliação das pessoas com DI.

Palavras-chave: Educação Especial; Deficiência intelectual; Identificação.

\footnotetext{
* Doutoranda em Educação Especial pela Universidade Federal de São Carlos (UFSCar). São Carlos, São Paulo, Brasil.

** Doutora em Educação Especial e Psicologia pela Universidade Federal de São Carlos (UFSCar). São Carlos, Sáo Paulo, Brasil.
} 


\section{Systematic review on evaluation for initial identification of students with intellectual disability}

\section{Abstract}

One of the services for attending special education students, including students with intellectual disabilities (ID), are Specialized Educational Attendance. Most of these students are first identified by the teachers (common room or resource room). From this, some questions arose, which, in order to be answered, the present research had the objective of investigating the forms of identification of students with ID, through a systematic review of scientific publications found in databases online in the period of 2010 to 2017 . This review was made from the relevant publications, selected according to results from 10 combinations of seven research terms. The search was done in the Lilacs and Portal de Periodicos de la Capes Journal Portal databases. After systematization and analysis of the content of the publications and extraction of information regarding the form of identification of this public, the categorization of the texts was carried out according to the themes of the studies found. It was found that the investigations do not present objective evaluation forms, describing them superficially, mentioning in the majority criteria such as those established by the American Association on Intellectual Deficiency and Development, an issue that does not only occur in Brazil, but also in other countries of Latin America, according to studies show. In view of the scarcity of results, the importance of conducting research that focuses on the systematization, standardization and dissemination of the forms of evaluation of people with ID are highlighted.

Keywords: Special education; Intelectual disability; Identification.

\section{Revisión sistemática sobre evaluación para identificación inicial de alumnos con discapacidad intelectual}

\section{Resumen}

Uno de los servicios para atención de los alumnos público de la educación especial, entre ellos los alumnos con discapacidad intelectual (DI), son los Atendimientos Educacionales Especializados. Gran parte de estos alumnos son identificados en un primer momento por los profesores (de la sala común o de la sala de recursos). A partir de eso, surgieron algunas cuestiones, las cuales, para ser respondidas, la presente investigación tuvo por objetivo investigar las formas de identificación de alumnos con DI, por medio de una revisión sistemática de publicaciones científicas encontradas en bases de datos online en el período 2010 a 2017. Esta revisión fue realizada de las publicaciones pertinentes, seleccionadas de acuerdo con resultados provenientes de 10 combinaciones entre siete términos de investigación. La búsqueda se dio en las 
bases de datos Lilacs y Portal de Periódicos de la Capes. Después de sistematización y análisis del contenido de las publicaciones y extracción de informaciones referentes a la forma de identificación de este público, se realizó la categorización de los textos de acuerdo con las temáticas de los estudios encontrados. Se constató que las investigaciones no presentan formas de evaluación objetivas, relatándolas superficialmente, mencionando en su mayoría criterios como los establecidos por la Asociación Americana sobre Deficiencia Intelectual y Desarrollo, cuestión que no ocurre sólo en Brasil, sino también en otros países de Latinoamérica, Según señalan los estudios realizados. En vista de la escasez de resultados, se resalta la importancia de la realización de investigaciones que enfoquen la sistematización, estandarización y divulgación de las formas de evaluación de las personas con DI.

Palabras clave: Educación Especial; Discapacidad intelectual; Identificación.

\section{Introdução}

A forma como a pessoa com deficiência intelectual (DI) foi vista ao longo do tempo e marcada por diferentes configurações, como misticismo, espetáculo, rejeição, extermínio, filantropia, segregação e exclusão. Já na década de 60 , iniciou-se um modelo diferenciado, denominado como integração. No referido modelo os alunos eram educados em classes especiais, separadamente, visando a normalização destes para o convívio em sociedade. Desta forma perpetuou-se a responsabilidade dos problemas centrada no aluno. Já na inclusão, momento posterior derivado da integração, e modelo atualmente mais defendido e recomendado, os alunos público alvo da Educação Especial $\left(\mathrm{PAEE}^{1}\right)$ frequentam as aulas nas mesmas salas que os demais alunos, visando sua inclusão no meio social. A mudança fundamental ocorrida em relação aos demais modelos foi de que a responsabilidade de adaptação passou a ser da escola (GARGHETTI; MEDEIROS; NUERNBERG, 2013).

Dentre os diferentes alunos PAEE matriculados nas escolas estão os alunos com DI. A Classificação Internacional de Funcionalidade, Incapacidade e Saúde (CIF) apresenta a deficiência como "problemas nas funçôes ou estruturas do corpo, tais como, um desvio ou perda significativos", sendo que as funçóes do corpo consistem nas "funçôes fisiológicas dos sistemas orgânicos (incluindo as funçôes psicológicas) " (OMS, 2004, p.200). A deficiência pode ser percebida a partir da observação do comportamento do indivíduo. Compreende-se, desta forma, que a CIF considera não somente as funções e/ou estruturas do corpo como deficiência, mas também a relação destas com a possibilidade de atuação em atividades cotidianas, participação social e fatores ambientais que possam de alguma forma influenciar negativamente na atuação social da pessoa com deficiência.

Ao longo do processo de reconhecimento das pessoas com DI como cidadâs muitas definiçóes e denominaçóes surgiram juntamente a novas teorias sobre esta população. A classificação mais atual descreve este público como pessoas que possuem uma deficiência caracterizada por limitaçôes significativas tanto no funcionamento intelectual (raciocínio, aprendizagem, resolução de problemas) como no comportamento adaptativo, que abrange uma gama de habilidades sociais e práticas cotidianas, 
originando-se antes dos 18 anos de idade (Associação Americana sobre Deficiência Intelectual e Desenvolvimento - AAIDD -, 2010). Nota-se que tal deficiência não está relacionada a algum transtorno ou doença mental necessariamente, assim como não é estática, partindo-se de intervenções individualizadas, resultando em benefícios para o progresso do indivíduo, melhorando suas condiçôes iniciais (GARGHETTI; MEDEIROS; NUERNBERG, 2013).

Atualmente a forma mais utilizada para identificação deste público ainda é por meio de instrumentos padronizados que medem o percentil de inteligência do indivíduo. Silva (2011) define os testes psicológicos como "medidas objetivas e padronizadas de uma amostra de comportamento" (p.7), envolvendo diferentes tarefas com objetivo de testar variados repertórios que, de acordo com a abordagem utilizada para desenvolvimento do teste, são formas de manifestação da inteligência do ser humano. Primi (2003) relata que os referidos testes são a forma de operacionalizar as teorias em comportamentos observáveis.

O interesse por esse tipo de mensuração se deu a partir de Esquirol, em 1838, que objetivou diferenciar insanidade de retardo mental (nomenclatura adotada à época). A partir de estudos criou-se critérios de definição, reunidos sob a forma de testes de inteligência, pautados em conteúdos verbais. Séguin, em 1837, fundou a primeira escola para educaçáo de crianças com retardo mental, que priorizava o ensino de tarefas não verbais, habilidades que, de acordo com a abordagem que o estudioso seguia, também mereciam atenção ao se verificar o repertório de pessoas com DI (SILVA, 2011).

Galton apresentava uma visão diferente em relação à avaliação da inteligência humana: o uso das habilidades de discriminação sensorial era o centro da forma de mensurar a inteligência humana. Um dos fatores que influenciou esta abordagem foi a maior facilidade em mensurar tais habilidades, em detrimento da mensuraçáo de aspectos mais subjetivos que permeiam a inteligência (SILVA, 2011).

Já no início do século XX, influenciadas pelas teorias de Galton, surgiram duas teorias extremas, sendo elas a de Spearman (em 1927), que definia que a inteligência poderia ser medida utilizando-se um fator geral, único, e a de Thurstone (em 1938), que defendia a existência de um conjunto de habilidades básicas que permitiam chegar à mensuraçáo da inteligência.

No Brasil o uso destes testes teve maior destaque em 1920, quando médicos os utilizavam para promover programas preventivos de saúde mental, bem como realizar diagnósticos de pessoas com problemas nesta área. O maior influenciador no país foi Binet.

Uma das teorias que mais é aceita no cenário atual é a chamada Teoria de Cattell-Horn-Carroll (CHC) das Habilidades Cognitivas, que apresenta uma visão multidimensional da inteligência. Sendo ela formada por dez fatores (inteligência fluída, inteligência cristalizada, conhecimento quantitativo, leitura e escrita, memória de curto prazo, processamento visual, processamento auditivo, capacidade de armazenamento e recuperação da memória de longo prazo, velocidade de processamento 
e rapidez de decisão), que envolvem linguagem, memória, recepção auditiva, raciocínio, velocidade cognitiva, percepção visual, produção de ideias e conhecimento e rendimento acadêmicos (PRIMI, 2003). Entretanto, ainda não existem testes que utilizem todas estas esferas como referência. $\mathrm{O}$ autor supracitado indica que sejam feitas combinaçôes de testes que meçam diferentes áreas, visando maior abrangência de habilidades do indivíduo a ser avaliado.

É fundamental conhecer o que o teste avalia, pois por trás de cada instrumento há uma teoria que define a inteligência de uma ou outra forma, mensurando-a, então, de maneiras distintas (PRIMI, 2003). Portanto, faz-se importante disseminar o conhecimento acerca dos testes, bem como a formaçáo dos aplicadores, não somente de como fazê-lo, mas também de como apresentar os resultados oriundos de sua aplicação, ressaltando não apenas as áreas deficitárias, como também aquelas para as quais o sujeito avaliado tem maior aptidão (PRIMI, 2003; SILVA, 2011). Nota-se que o resultado destes testes não é determinante e imutável, mas sim um potencial e indicação de áreas que necessitam ser desenvolvidas (LEVY, 2016). Deve-se ressaltar que o ambiente e as experiências de cada indivíduo podem influenciar em seu desempenho (PRIMI, 2003; SILVA, 2011).

Moreira (2011) relata, ainda, que a idade de diagnóstico está fortemente associada ao grau de severidade da deficiência apresentada pelo indivíduo, bem como às características físicas apresentadas, como, nos casos de indivíduos que possuem Síndrome de Down. O momento do diagnóstico é de fundamental relevância, visto que quanto mais precocemente são realizadas as intervençôes (pedagógicas e terapêuticas), maiores e melhores serão as condiçóes para que o indivíduo se desenvolva o mais plenamente possível quanto ao seu potencial.

A dificuldade de normatizar formas de identificação do alunado com DI pode sofrer influência das diferentes formas de definiçấo do conceito de DI bem como do conceito de inteligência.

Veltrone e Mendes (2011) analisaram as propostas referentes à identificação de crianças com DI, tendo como base de dados documentos legais, normativos e orientadores oficiais do Ministério da Educação e Cultura (MEC). As autoras constataram a existência de recomendaçóes controversas. Parte dos documentos orienta que tal identificação deve ser realizada por profissionais da saúde ou por equipes multidisciplinares, envolvendo especialistas de diferentes áreas. Já outros indicam que a identificação desta população seja desempenhada pelos professores, os quais têm maior conhecimento acerca dos comportamentos e contexto no qual o aluno está inserido. Esta forma de avaliação é atualmente respaldada pela orientação dada pelo Ministério da Educação por meio da nota técnica no4 do ano de 2014, a qual afirma que

\footnotetext{
não se pode considerar imprescindível a apresentação de laudo médico (diagnóstico clínico) por parte do aluno com deficiência, transtornos globais do desenvolvimento ou altas habilidades/superdotação, uma vez que o AEE caracteriza-se por atendimento pedagógico e não clínico (BRASIL, 2014) (destaque realizado pelas autoras).
} 
Apesar de não ser necessária, segundo esta nota técnica, a apresentação de laudo médico, este fato traz diversas questôes, dentre elas, uma das questôes que suscitou este estudo foi: quais as formas que vem sendo utilizadas para a realizaçáo da avaliação para identificar se o aluno 'tem' DI?

Nos resultados da revisão bibliográfica de artigos sobre DI realizada por Milian et al (2013) na base de dados SciELO, de 2000 a 2012, constatou-se que o tema de avaliação para o diagnóstico de pessoas com DI foi pouco explorado pelas publicaçóes neste período.

Tendo em vista que em grande parte dos casos a DI torna-se mais evidente ao ingressar nas primeiras fases escolares, cuja principal finalidade inicialmente é de ensinar as habilidades de leitura e de escrita, as quais envolvem um raciocínio mais abstrato e arbitrário, surgiram as seguintes questóes: I) como é realizada a identificação desses alunos?; II) quais os instrumentos indicados para a realização desta identificação?; III) quais as formas que vem sendo utilizadas para a avaliação para identificar se o aluno 'tem' deficiência intelectual? IV) há uma padronização nacional para a identificaçáo dos alunos com DI? Para responder estes questionamentos este estudo teve por objetivo investigar as formas de identificaçáo de alunos com deficiência intelectual, por meio de revisão sistemática de publicaçôes científicas encontradas em bases de dados online dos últimos sete anos referentes ao tema, ou seja, o período de 2010 a 2017.

\section{Método}

O presente estudo trata-se de uma pesquisa de revisão sistemática, que de acordo com Hohendorff (2014, p. 41) tem por objetivo "sumarizar pesquisas prévias para responder questóes, testar hipóteses ou reunir evidências". Tais publicaçóes foram extraídas das bases de dados Lilacs e Portal de Periódicos da Capes. Foram utilizados como descritores as combinaçóes de palavras: Identificação OU diagnóstico OU avaliação OU instrumento OU teste + deficiência intelectual OU deficiente intelectual, totalizando dez combinaçóes a serem pesquisadas. $O$ período de abrangência foi de 2010 a 2017, tendo em vista a nova definição de DI adotada pela AAIDD. As áreas de interesse para esta pesquisa foram a educação e a psicologia.

Optou-se pela realização da revisão sistemática tendo em vista que por meio desta forma de revisão é possível ir além de apenas organizar os dados, visto que este método de pesquisa se propóe a refletir e interpretar os dados. Costa e Zoltowski (2014, p.56) definem este método como mais que uma "simples relaçáo cronológica ou uma exposição linear e descritiva de uma temática, pois a revisão sistemática deve se constituir em um trabalho reflexivo, crítico e compreensivo a respeito do material analisado".

Para a revisão sistemática foram utilizados artigos científicos de bases de dados online. 


\section{Equipamentos e materiais}

Utilizou-se um notebook com conexão à internet para a realização da pesquisa. Nota-se que os dados foram coletados por meio de pesquisa com uso de rede da Universidade Federal de São Carlos, que tem uma rede de credenciamento com algumas bases de dados, permitindo acesso a textos completos que talvez não sejam possíveis sem o acesso CAFe (acesso remoto a arquivos pela rede da Comunidade Acadêmica Federada), desta forma, é possível que publicaçóes encontradas neste artigo, sejam arquivos restritos quando em acesso pelo público.

Para organização dos dados obtidos após leitura e a sistematização da extração das informaçôes pertinentes se deram por meio do uso do programa Excel da Microsoft.

\section{Procedimento de coleta de dados}

A partir da escolha das palavras-chave que foram utilizadas, estabeleceram-se critérios para inclusão dos estudos a serem analisados: a) ser uma forma de publicação em artigo e com possibilidade de acesso ao texto completo; b) tratar da avaliação como forma de identificação do alunado da DI; c) estar em língua portuguesa brasileira; e d) tratar da realidade brasileira. Já os critérios de exclusão abrangem: a) publicaçóes que náo sejam artigos (resumos, resumos expandidos, trabalhos apresentados em congressos, relatórios de bolsas de financiamento de pesquisas, dissertaçóes, teses); b) publicaçôes não acessíveis na forma online gratuita; c) tratar de formas de avaliaçáo de pessoas com DI que não estejam relacionadas à identificaçáo ou diagnóstico destes sujeitos, como avaliação da aprendizagem dos alunos, avaliação de intervençôes e/ou procedimentos pedagógicos, terapêuticos ou médicos; d) o texto não estar escrito em língua portuguesa brasileira; e e) não retratar a realidade brasileira.

\section{Procedimento de análise de dados}

A busca retornou 39 artigos que, por meio da leitura do título aparentavam ser pertinentes à pesquisa. A partir disso, categorizou-se as publicaçóes de acordo com a temática. Nota-se que houve prevalência de trabalhos encontrados que retratam a realidade de outros países e estâo em outra língua (10) e que estão em outra língua, apesar de abordarem a realidade do Brasil (3). Contudo, estes três artigos não atendem ou se aproximam ao objetivo proposto por este estudo. Após a leitura dos resumos, objetivos e dos métodos das publicaçóes, 15 artigos foram excluídos, por náo corroborarem com o objetivo proposto por esse artigo (Figura 1). Do total de artigos selecionados, após a leitura integral, restaram 11 artigos (Quadro 1), cuja descrição das características mais pertinentes é realizada a seguir, na ordem apresentada na figura 1. 
Figura 1- Quantidade e motivos de exclusão de publicaçốes durante o processo de seleçấo de artigos

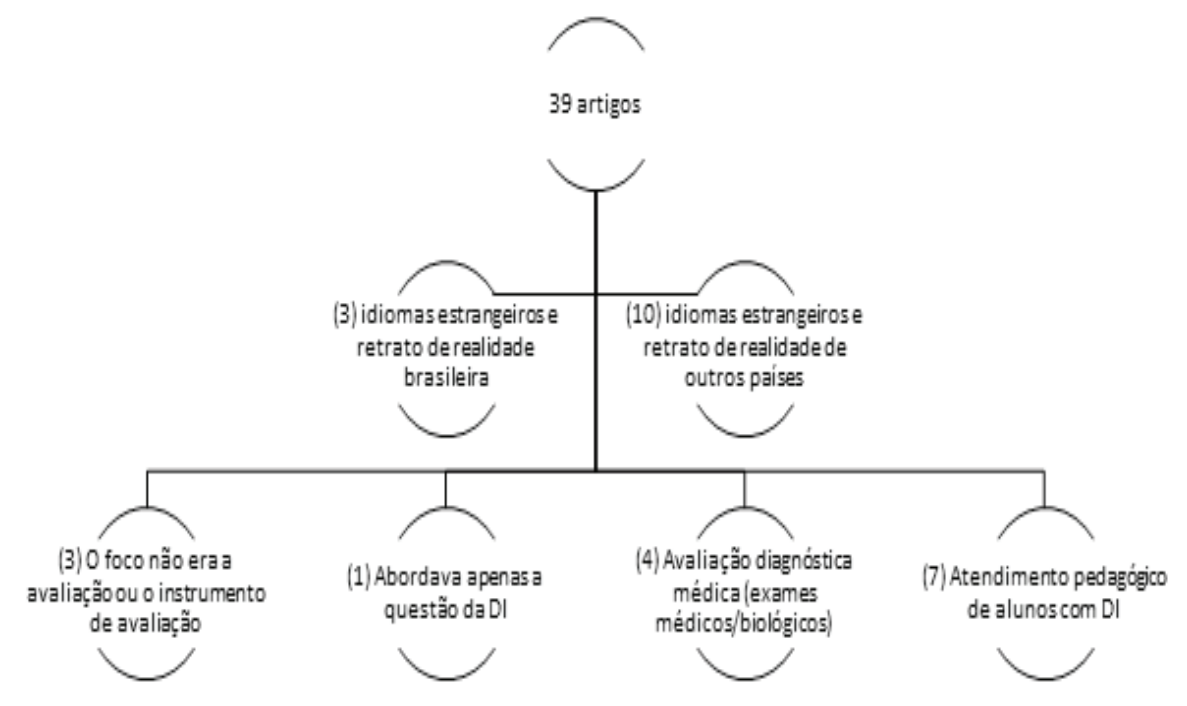

Fontes: as autoras.

A partir dos dados encontrados realizou-se a categorização de acordo com as os objetivos dos estudos (COSTA; ZOLTOWSKI, 2014), a saber: 1) Avaliação de habilidades específicas; 2) Adaptação e validação de testes; e 3) Avaliação de inteligência de outros públicos. Para a classificação final dos artigos realizou-se uma análise de concordância entre dois juízes com formação em Licenciatura em Educação Especial, que resultou em $100 \%$ de compatibilidade. Observa-se que cada estudo poderia ser qualificado em apenas uma das categorias.

Objetivou-se extrair os seguintes elementos: como profissionais que realizam a avaliaçáo, como é feita e tipo de avaliação utilizada, visando conhecer as práticas referentes à identificação dos alunos com DI e, desta forma, possibilitar a orientaçáo aos profissionais da educação, para além apenas do foco nas habilidades acadêmicas.

\section{Resultados}

Inicialmente pretendia-se que as publicaçôes provenientes da revisão sistemática fornecessem subsídios para orientar a prática da avaliação para identificação das pessoas com DI por profissionais da educação. No entanto, não foram localizados artigos que tratassem de diagnóstico da deficiência no parâmetro pré-estabelecido (ver quadro 1 ). 
Quadro 1- Caracterização dos artigos analisados: categoria, título e ano de publicação

\begin{tabular}{|c|c|c|c|}
\hline Categoria & Título do artigo & Autores & Ano de publicação \\
\hline $\begin{array}{l}\text { Avaliação de } \\
\text { habilidades } \\
\text { específicas }\end{array}$ & 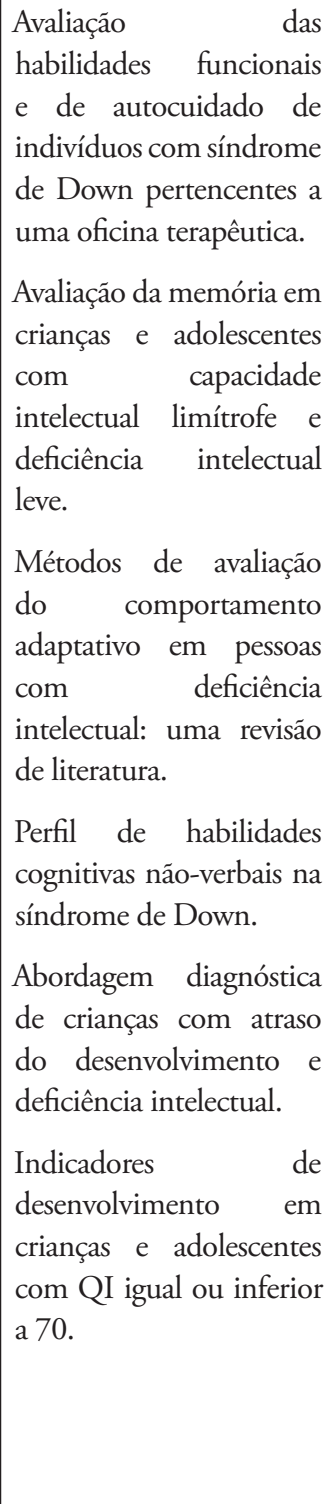 & $\begin{array}{l}\text { Marielza Regina } \\
\text { Ismael Martins; Maria } \\
\text { Amelia Branco Fecuri; } \\
\text { Marta Alves Arroyo; } \\
\text { Marcia Taves Parisi } \\
\text { Amanda Morão } \\
\text { Pereira; } \\
\text { Carolina } \\
\text { Araújo; } \\
\text { Sylvia Maria Ciasca; } \\
\text { Sônia das Dores } \\
\text { Rodrigues. } \\
\text { Elizângela Fernandes } \\
\text { Ferreira; } \\
\text { Mey de Abreu Van } \\
\text { Munster. } \\
\text { Tatiana } \\
\text { Mecca; } \\
\text { Cindy Pereira de } \\
\text { Almeida } \\
\text { Morão; } \\
\text { Patrícia Botelho da } \\
\text { Silva; } \\
\text { Elizeu Coutinho de } \\
\text { Macedo. } \\
\text { Raquel Boy } \\
\text { Fernanda } \\
\text { Souza; } \\
\text { Batista }\end{array}$ & $\begin{array}{l}2015 \\
2015 \\
2016\end{array}$ \\
\hline
\end{tabular}




\begin{tabular}{|c|c|c|c|}
\hline Categoria & Título do artigo & Autores & Ano de publicaçáo \\
\hline $\begin{array}{l}\text { Adaptação e } \\
\text { validação de testes }\end{array}$ & $\begin{array}{l}\text { Inventário de } \\
\text { Avaliaçáo Pediátrica de } \\
\text { Incapacidade (PEDI): } \\
\text { aplicabilidader no } \\
\text { diagnóstico de } \\
\text { transtorno invasivo } \\
\text { do desenvolvimento e } \\
\text { retardo mental. } \\
\text { Evidência de validade } \\
\text { do diagnóstico da } \\
\text { leitura e escrita (DLE) } \\
\text { em relação ao WISC- } \\
\text { III em deficientes } \\
\text { intelectuais. } \\
\text { A Escala de } \\
\text { Intensidade r de } \\
\text { Suporte - SIS no } \\
\text { Brasil. }\end{array}$ & $\begin{array}{l}\text { Roseli Paicheco; } \\
\text { Julianna Di Matteo; } \\
\text { Simone Cucolicchio; } \\
\text { Claudio Gomes; } \\
\text { Marcio Falcão } \\
\text { Simone; } \\
\text { Francisco Baptista } \\
\text { Assumpçâo Junior. } \\
\text { Priscila Benitez; } \\
\text { Máyra Laís de } \\
\text { Carvalho Gomes; } \\
\text { Patrícia Waltz Schelini; } \\
\text { Camila Domeniconi. } \\
\text { Maria Amelia } \\
\text { Almeida, } \\
\text { Iasmin Zanchi Boueri, } \\
\text { Lidia Maria Marson } \\
\text { Postalli }\end{array}$ & 2015 \\
\hline $\begin{array}{ll}\text { Avaliação } & \text { de } \\
\text { inteligência } & \text { de } \\
\text { outros públicos } & \end{array}$ & $\begin{array}{l}\text { Desempenho Criativo } \\
\text { e suas Relaçóes com } \\
\text { Diferentes Medidas } \\
\text { de } r \text { Inteligência } \\
\text { em } \\
\text { com Dislexia do } \\
\text { Desenvolvimento: } \\
\text { Um Estudo } \\
\text { Ex plor a tório. }\end{array}$ & $\begin{array}{l}\text { Rauni Jande Roama } \\
\text { Alves; Tatiana de } \\
\text { Cassia Nakano }\end{array}$ & 2015 \\
\hline $\begin{array}{ll}\text { Avaliação } & \text { de } \\
\text { inteligência } & \text { de } \\
\text { outros públicos } & \end{array}$ & $\begin{array}{l}\text { Avaliação da } \\
\text { inteligência de } \\
\text { crianças deficientes } \\
\text { visuais: estudo } \\
\text { exploratório da } \\
\text { adequação de itens }\end{array}$ & $\begin{array}{l}\text { Carolina } \\
\text { Campos; } \\
\text { Tatiana de Cássia } \\
\text { Nakano. }\end{array}$ & 2017 \\
\hline
\end{tabular}

Fontes: as autoras. 
Na categoria "Avaliação de habilidades específicas" o estudo de Martins, Fecuri, Arroyo e Parisi (2013) avalia o desempenho de crianças com Síndrome de Down quanto às habilidades de autocuidados, funçôes sociais e mobilidade, utilizando o instrumento PEDI (Pediatric Evaluation of Disability Inventory), que avalia tais habilidades por meio de 73, 65 e 59 itens, respectivamente. $\mathrm{O}$ artigo se faz pertinente por apresentar os principais subitens avaliados em cada área, assim como porque estas são três das dez áreas de condutas adaptativas, fundamentais para a avaliação de pessoas com DI.

A pesquisa de Pereira et. al (2015) utiliza três diferentes instrumentos padronizados para avaliaçáo de memória em sujeitos com DI leve, limítrofe e sem deficiência. Dois deles (WISC-IV e Teste de Aprendizagem Auditivo-Verbal de Rey (RAVLT) são de uso restrito a psicólogos, contudo, o terceiro, o Teste de Blocos de Corsi (TBC), que avalia memória operacional, permite a aplicação por profissionais de outras áreas. Outra ressalva é que no artigo as autoras não apresentam uma descrição detalhada do teste ou sua forma de aplicação, apenas menciona o que o mesmo avalia e, posteriormente, os resultados da aplicaçáo na população alvo da pesquisa.

Dentre os estudos encontrados, por ser o que mais se aproxima do que se objetivava obter neste estudo, considera-se importante relatar a pesquisa de Ferreira e Van Munster, do ano de 2015. Neste estudo as autoras realizaram uma pesquisa bibliográfica em bases de dados online sobre a temática de avaliação de condutas adaptativas em pessoas com DI. Como resultados, encontraram diferentes testes padronizados em uso, contudo estes são, em maior parte, direcionados para profissionais da área da saúde. Já quando as avaliaçôes eram mais dirigidos para a área educacional, constatou-se maioria de uso de avaliaçóes não padronizadas e realizadas de diferentes formas. Há, no artigo, a indicação de habilidades avaliadas pelos instrumentos resultantes da pesquisa, o que pode contribuir para a sistematização de uma nova forma avaliativa de cunho educacional.

Embora seja um estudo voltado para uma população específica que compõe o público de pessoas com DI, Mecca et al (2015) apresentam quatro subitens da Escala Internacional de Inteligência Leiter-R. Este é um teste que mensura diferentes habilidades (discriminação, reconhecimento, retenção visual, memória de trabalho, flexibilização atencional, dentre outras habilidades) por meio de atividades não-verbais, e descrevem como avaliar, o que é utilizado em cada atividade, o objetivo, quais habilidades são mensuradas e habilidades necessárias para realiza-las, tornando possível compreender melhor como e porque avaliar estas habilidades. Tal forma de avaliação (não-verbal) se faz importante, devido à comum dificuldade de verbalização de pessoas com suspeita de diagnóstico de DI.

Ainda que seja voltado para a área médica, o artigo de Boy (2016) indica alguns elementos necessários para se avaliar principalmente no que se refere à anamnese com os pais ou responsáveis mais próximos à criança a ser avaliada, tais como histórico familiar e gestacional e observação de comportamentos tais como resposta ao olhar, ao contato tátil e movimentos repetitivos. 
A pesquisa realizada por Souza e Batista (2016), apesar de não apresentar o instrumento utilizado para avaliação dos indicadores desenvolvimentais de dois alunos com quociente de inteligência (QI) indicativo de DI, apresenta, nos resultados, quadros com os itens e subitens avaliados e diferentes formas de avaliação (entrevista com família e escola), atividade avaliativa e observação do comportamento durante a atividade proposta. Desta forma, se faz um meio de orientar e testar se esta forma é eficaz para a avaliação para diagnóstico pedagógico de pessoas com DI.

Já na categoria de adaptação e validação de instrumentos, a pesquisa de Paicheco et al (2010), mais voltada para a área da saúde, o que pode ser observado pela nomenclatura utilizada para se referir à pessoa com DI (retardo mental), menciona brevemente um dos testes padronizados que pode ser usado para identificação desse público e apresenta outro instrumento, o Inventário de Avaliação Pediátrica de Incapacidade (PEDI), já validado no Brasil, que pode direcionar para formas de mensuração dos âmbitos nele avaliados, sendo eles autocuidado, mobilidade e função social. Os autores apresentam o instrumento de forma geral, explicitando os objetivos da avaliação em cada uma das três partes que o compóe. Ao final, concluiu-se que este instrumento pode auxiliar na identificação de prejuízos no desempenho da criança, propiciando a possibilidade de planejamento de intervençáo visando o desenvolvimento das habilidades necessárias.

Benitez et al (2015), realizaram um estudo em que se comparou um teste de habilidades que envolvem leitura e escrita (Diagnóstico de Leitura e Escrita) a um teste psicológico padronizado (WISC-III), aplicando ambos com 16 sujeitos com idade entre sete e 15 anos. Constatou-se algumas correlaçóes moderadas e significantes entre as áreas avaliadas no teste psicológico e certas habilidades mensuradas no instrumento de leitura e escrita. Ainda que não apresente a forma de avaliação utilizada em ambos os testes de maneira mais detalhada, este estudo demonstra a importância de se avaliar habilidades não apenas de leitura e de escrita, como também habilidades anteriores, pré-requisitos, para a aquisição desse repertório, indicando caminhos para se avaliar algumas áreas do comportamento da pessoa a ser (ou náo) diagnosticada com DI.

O artigo de Almeida, Boueri e Postalli (2016) apresenta uma pesquisa que está em andamento, contudo apresenta etapas iniciais de adaptação da escala SIS (Escala de Intensidade de Suporte) para o contexto brasileiro, o que demonstra um princípio de sistematização de um modo de avaliação de comportamentos adaptativos em jovens e adultos com DI, representando um avanço na estruturação da forma de identificar este público.

Por fim, na categoria de avaliação de inteligência de outros públicos, a pesquisa realizada por Alves e Nakano (2015) avaliou o desempenho criativo e associo-o ao desempenho em diferentes medidas de inteligência em crianças com dislexia. Utilizou-se um teste padronizado para mensurar a criatividade (Teste de Criatividade Figural Infantil) e três testes para avaliar a inteligência (Matrizes Progressivas Coloridas de Raven, Escala de Inteligência Wechsler para Crianças e Desenho da Figura Humana). Constatou-se que nesta população não há uma forte correlação entre inteligência 
e criatividade, contudo os autores valem-se de um fator fundamentado na teoria de Renzulli sobre a inter-relação entre criatividade e inteligência em pessoas com altas habilidades para a necessidade de maiores investigaçóes sobre a temática com a população estudada, bem como com outras populaçôes.

O estudo de Campos e Nakano (2017), embora tenha como participantes crianças com deficiência visual e crianças sem deficiências, apresenta habilidades a serem medidas para a avaliação da inteligência, ademais, propôe formas de avaliar o desempenho em: raciocínio verbal, memória e raciocínio lógico. Deve-se enfatizar que, segundo as autoras, essa bateria de testes é recomendada para aplicação com crianças com idade entre 7 e 12 anos.

\section{Discussão}

Ao analisar o conteúdo dos artigos selecionados observou-se a escassa quantidade de estudos que abordam a temática de avaliação para identificação de pessoas com DI. Nota-se o predomínio de uso de testes padronizados que mensuram as habilidades cognitivas dos sujeitos, sendo que os mais utilizados são a Escala de Inteligência Wechsler para Crianças (WISC), Matrizes Progressivas Coloridas de Raven (RAVEN) e Inventário de Avaliação Pediátrica de Incapacidade (PEDI). Nota-se que destes, os dois primeiros são de uso restrito a psicólogos e o último náo possui restriçóes, contudo o instrumento náo é facilmente acessível.

Nota-se, também, a necessidade de atenção à avaliação de adolescentes e adultos, público abordado por apenas um estudo, dentre os 11 explorados. Evidencia-se que um dos itens para se avaliar o comportamento adaptativo é o comportamento em situaçáo e/ou local de trabalho. Isto posto, refletir e pesquisar acerca de formas de avaliar os públicos jovem e adulto é um fator fundamental.

Ao contrário do que se encontrou no estudo de Veltrone e Mendes (2011), investigando os documentos legais, as pesquisas resultantes do presente estudo estão enviesadas para a avaliação por parte de profissionais da saúde, ainda que comumente esta deficiência seja notada em situação escolar, quando não há a presença de fenótipos específicos nos indivíduos (como na Síndrome de Down, por exemplo). Este dado corrobora com o achado da pesquisa de Ferreira e Van Munster (2015), que constatou o uso de testes padronizados diversificados e, em sua maioria dirigidos a profissionais da área da saúde.

Dos testes apresentados pelas pesquisas, observa-se que parte delas detalha o que os instrumentos medem, contudo, outras não o fazem. Primi (2003) e Silva (2011) afirmam a importância de disseminar o conhecimento acerca dos testes. Ressalta também que os resultados de sua aplicaçáo propiciem o conhecimento das áreas deficitárias e daquelas para as quais o indivíduo apresenta maior facilidade, proporcionando um melhor panorama para o posterior planejamento de intervençóes educacionais, terapêuticas e médicas.

A escassez de resultados pertinentes e significativo volume de publicaçóes referentes à realidade de países como Chile e México propiciou que se realizasse um 
comparativo entre as realidades. A realidade chilena, apesar de apresentar orientaçôes gerais sobre alguns instrumentos padronizados que podem ser utilizados para tal avaliação, os estudos de Montero e Lagos (2011) e Alarcón-Leiva e Sepúlveda-Dote (2014) apresentam pontos semelhantes à realidade encontrada no Brasil, com demandas como necessidade de formação para profissionais que participam da avaliação de pessoas com DI, orientaçóes mais claras, formas de avaliação padronizadas e validadas para a realidade local e aplicação de conhecimentos científicos na realidade cotidiana, visando maior eficiência no diagnóstico.

Um exemplo de estudo que se faz necessário realizar e disseminar é o realizado por Cánovas, Martínez, Sánchez-Joya e Roldán-Tapia (2010), que pretenderam propor formas de avaliação para pessoas com DI, transtornos globais do desenvolvimento e atrasos psicomotores, subdividindo os testes em aplicáveis com sujeitos com idade menor que três anos e com maiores de três anos. Os autores apresentam diversos testes padronizados para a avaliação de cada componente que deve ser avaliado em cada caso (das três populaçôes investigadas no estudo). Apresenta, ainda, consideraçôes necessárias para que seja realizada uma avaliação com o máximo de precisão diagnóstica, informando aspectos a serem considerados na realização de um diagnóstico diferencial.

Ao investigar a temática na América Latina, Lazcano-Ponce, et al. (2013) apontam para o fato de que os critérios contidos nas escalas comumente são mais sensíveis a pessoas com deficiências mais severas, deixando à margem pessoas com deficiências leves a moderadas e que há, ainda, a questão de aplicaçâo por idade. Outro fator em comum nesta regiẫo é a carência de guias, normas ou instrumentos padronizados atualizados na América Latina ou que sejam adaptados para a realidade desta região; necessidade de articulação entre pesquisas e prática; uso do conhecimento científico para fundamentar as açóes desde a identificação das pessoas com DI até sua participação social, sua entrada no mercado de trabalho e vida independente; profissionalização das pessoas que atuam no âmbito da avaliação, atenção e intervenção realizadas com pessoas com DI e envolver esferas diferentes, não apenas da saúde, envolvendo um trabalho interdisciplinar.

Observa-se que os estudos analisados apresentam testes que mensuram habilidades diversas, contudo em sua maioria estas estão voltadas para a concepção de DI anterior, a qual não considerava as áreas do comportamento adaptativo, definidas como habilidades conceituais, sociais e práticas, utilizadas no cotidiano (comunicação, habilidades sociais, autocuidado, habilidades de vida diária, saúde e segurança, atuação na comunidade, independência na locomoção, habilidades acadêmicas e funcionais, lazer e trabalho) (AAIDD, 2010; ALARCÓN-LEIVA; SEPÚLVEDA-DOTE, 2014). É fundamental para a evolução da avaliação desse público que se sistematize e haja maior atenção para a criação, adaptação e validação de instrumentos que utilizem critérios comuns para avaliar essas habilidades, considerando-se o contexto em que o sujeito se encontra (STELMACHUK; HAYASHI, 2015). 


\section{Conclusão}

A partir da investigação das formas de identificação de alunos com DI, por meio da revisão sistemática de publicaçôes científicas encontradas em bases de dados online no período de 2010 a 2017, observou-se a ausência de estudos que abordassem especificamente esta temática, sendo necessário ampliar os critérios para a obtenção de resultados próximos ao almejado.

Nota-se que, apesar da mudança de nomenclatura deste público, e do uso dos termos "deficiência intelectual" e "deficiente intelectual" para a realização da busca, houve registro de artigos que utilizavam terminologias desatualizadas, tais como "deficiência mental" e, até mesmo, "retardo mental", o que pode indicar não apenas uma desatualização de nomenclatura, como também influência na forma de enxergar e avaliar a pessoa com DI, ainda sob a perspectiva do modelo médico.

Além do modo abrangente como são dadas as instruçôes de avaliação pedagógica por documentos normativos e orientadores, constatou-se uma ausência de formas de avaliaçóes completas e que sejam voltadas para a área educacional, predominando o uso de testes padronizados com aplicaçáo restrita a psicólogos.

Náo se pode deixar de ressaltar a quantidade significativa de estudos internacionais, principalmente retratando a realidade chilena e mexicana, em que comumente são retratados o uso, a validação ou a adaptação de testes padronizados sobre métodos de avaliação de comportamento adaptativo em alunos com DI, o que evidencia a necessidade de validação e adaptação de testes acessíveis aos profissionais da educação para a realidade brasileira.

Faz-se necessário realizar e disseminar estudos realizados sobre identificação de pessoas com DI, que apresentem testes padronizados para a avaliaçáo de cada componente que deve ser avaliado e com o maior grau de precisão, indicando particularidades a serem consideradas ao se avaliar uma pessoa com DI.

Estudos desta natureza são importantes para a disseminação e sistematização das formas de avaliar, assim como orientar os profissionais que possuem esta demanda, mas que não possuem conhecimento acerca destes instrumentos, como vem sendo apontado por pesquisas recentes.

Os estudos encontrados apresentam sugestóes importantes para o avanço no que se refere à avaliação diagnóstica de pessoas com DI: provimento de recursos para adaptaçóes e/ou elaboração de instrumentos padronizados para a avaliaçáo para diagnosticar pessoas com DI e importância de investimento em formação profissional específica para a atuação neste âmbito, visto a necessidade de ter conhecimentos específicos e domínio sob conceitos e formas de avaliação diagnóstica.

Como limitaçôes do estudo constata-se a importância de explorar publicaçóes mais antigas, uso de nomenclaturas similares a "deficiência intelectual". Ainda, para um panorama mais significativo desse cenário, é fundamental que pesquisas sejam realizadas incluindo-se dissertaçóes e teses. 


\section{Referências}

AAIDD. Intellectual disability: definition, classification and systems of supports. 11th ed. Washington (DC): American Association on Intellectual and Developmental Disabilities, 2010

ALARCÓN-LEIVA, Jorge; SEPÚLVEDA-DOTE, Maribel. La conducta adaptativa como criterio diagnóstico de discapacidad intelectual en estudiantes de Chile. Rev. latinoam. cienc. soc. nińez juv, Manizales, v. 12, n. 1, p. 187-199, jan. 2014. Disponível em: <http://www.scielo.org.co/scielo.php?script=sci_arttext\&pi$\mathrm{d}=$ S1692-715X2014000100011\&lng=pt\&nrm=iso >. Acesso em: 17 nov. 2017.

ALMEIDA, Maria Amélia; BOUERI, Iasmin Zanchi; POSTALLI, Lidia Maria Marson. A Escala de Intensidade de Suporte - SIS no Brasil. Journal of Research in Special Education Needs, v. 16, 2016, p. 60-64.

ALVES, R. J. R.; NAKANO, T. C. Desempenho criativo e suas relaçōes com diferentes medidas de inteligência em crianças com dislexia do desenvolvimento: um estudo exploratório. Psicol. Reflex. Crit., Porto Alegre, v.28, n.2, p.280-291, 2015. Disponível em: <http://www.scielo.br/scielo.php?script=sci_arttext\&pi$\mathrm{d}=$ S0102-79722015000200280\&lng=en\&nrm=iso >. Acesso em: 17 nov. 2017.

BENITEZ, Priscila. et al. Evidência de validade do diagnóstico da leitura e escrita (DLE) em relação ao WISC -III em deficientes intelectuais. Bol. Psicol., São Paulo, v. 65, n. 142, p. 83-96, 2015. Disponível em <http:// pepsic.bvsalud.org/scielo.php?script=sci_arttext\&pid=S0006-59432015000100008\&lng=pt\&nrm=iso $>$. Acesso em: 07 nov. 2017.

BOY, Raquel. Abordagem diagnóstica de crianças com atraso do desenvolvimento e deficiência intelectual. Revista Hospital Universitário Pedro Ernesto. v.15, n.2, 2016, p. 177-186.

BRASIL, Ministério da Educaçấo e Cultura. Nota Técnica n.4 de 23 de janeiro de 2014. Orientação quanto a documentos comprobatórios de alunos com deficiência, transtornos globais do desenvolvimento e altas habilidades/superdotação no Censo Escolar. Disponível em: <http://portal.mec.gov.br/index.php?option=com_docman\&view=download\&alias=15898-nott04-secadi-dpee-23012014\&category_slug=julho-2014- pdf\&Itemid=30192 >. Acesso em: 05 abr. 2017.

CAMPOS, Carolina Rosa; NAKANO, Tatiana de Cássia. Avaliaçăo da inteligência de crianças deficientes visuais: proposta de instrumento, v. 34, n. 2, p. 406-419. Disponível em: <http://www.scielo.br/scielo.php?script=sci_arttext\&pid=S1414-98932014000200011\&lng=p\&nrm=iso>. Acesso em: 07 nov. 2017.

CÁNOVAS, Rosa et al . Retraso mental y psicomotor en la primera infancia: Revisión de la literatura y propuesta de un protocolo de valoración neuropsicológica. Cuad. neuropsicol., Santiago, v. 4, n. 2, p. 162-185, 2010. Disponível em: <http://pepsic.bvsalud.org/scielo.php?script=sci_arttext\&pi$\mathrm{d}=$ S0718-41232010000200005\&lng=es\&nrm=iso >. Acesso em: 07 nov 2017.

COSTA, A. B.; ZOLTOWSKI, A. C. Como escrever um artigo de revisáo sistemática. In: S. H. KOLLER, M. C. P. COUTO; J. V. HOHENDORFF. Manual para produção científica. Porto Alegre: Penso, 2014, p.55-70.

FERREIRA, Elizângela Fernandes; VAN MUNSTER, Mey de Abreu. Métodos de avaliação do comportamento adaptativo em pessoas com deficiência intelectual: uma revisão de literatura. Revista Educaçáo Especial, Santa Maria, p. 193-208, dez. 2014. ISSN 1984-686X. Disponível em: <https://periodicos.ufsm.br/educacaoespecial/article/view/14339>. Acesso em: 7 nov. 2017.

GARGHETTI, F. C.; MEDEIROS, J. G.; NUERNBERG, A. H. Breve história da deficiência intelectual. Revista Electrónica de Investigación y Docencia (REID), 10, Jul. 2013, p. 101-116. Disponível em: <http:// revistaselectronicas.ujaen.es/index.php/reid/article/view/994/820>. Acesso em: 14 jan. 2017.

HOHENDORFF, J. V. Como escrever um artigo de revisáo de literatura. In: S. H. KOLLER, M. C. P. COUTO; J. V. HOHENDORFF. Manual para produçáo científica. Porto Alegre: Penso, 2014, p.39-54.

LAZCANO-PONCE, Eduardo, et al. Trastornos del desarrollo intelectual en America Latina: un marco para establecer las prioridades politicas de investigacion y atencion. Revista Panamericana de Salud Publica, vol. 34, no. 3, 2013, p. 204-209. Disponível em: <https://www.scielosp.org/pdf/rpsp/v34n3/09.pdf>. Acesso em: 17 Nov. 2017.

LEVY, J. História da psicologia sem as partes chatas: tudo o que você sempre quis saber sobre o comportamento humano e nem Freud conseguiu explicar. Trad. Mário Molina. São Paulo: Cultrix, 2016, 150p.

MARTINS, M. R. I. et al. Avaliação das habilidades funcionais e de autocuidado de indivíduos com síndrome de Down pertencentes a uma oficina terapêutica. Rev. CEFAC, São Paulo, v.15, n.2, p.361-365, 2013. Disponível em: <http://www.scielo.br/scielo.php?script=sci_arttext\&pid=S1516-18462013000200012\&lng=en\&nrm=iso>. Acesso em: 07 nov. 2017. 
MECCA, Tatiana Pontrelli. et al . Perfil de Habilidades Cognitivas Não-Verbais na Síndrome de Down. Revista brasileira de educaçáo especial, Marília, v. 21, n. 2, 2015, p. 213-228. Disponível em: <http://www. scielo.br/scielo.php?script=sci_arttext\&pid=S1413-65382015000200213\&lng=en\&nrm=iso >. Acesso em: 07 nov. 2017.

MILIAN, Queila Guise et al . Deficiência intelectual: doze anos de publicaçôes na base SciELO. Rev. psicopedag., São Paulo, v. 30, n. 91, p. 64-73, 2013. Disponível em: <http://pepsic.bvsalud.org/scielo.php?script=sci_arttext\&pid=S0103-84862013000100008\&lng=pt\&nrm=iso >. Acesso em: 27 nov. 2017.

MONTERO, Delfín; LAGOS, Juan. Conducta adaptativa y discapacidad intelectual: 50 años de historia y su incipiente desarrollo en la educación en Chile. Estud. pedagóg., Valdivia , v. 37, n. 2, p. 345-361, 2011 . Disponível em: <https://scielo.conicyt.cl/scielo.php?script=sci_arttext\&pi$\mathrm{d}=$ S0718-07052011000200021\&lng=pt\&nrm=iso $>$. Acesso em: 27 nov. 2017.

MOREIRA, L. M. A. Deficiência intelectual: conceitos e causas. In: Algumas abordagens da educação sexual na deficiência intelectual. 3.ed. Salvador: EDUFBA, 2011, pp. 35-41. Bahia de todos collection. ISBN 97885-2321157-8.

OMS. Classificação Internacional de Funcionalidade, Incapacidade e Saúde - CIF. Lisboa; 2004.

PAICHECO, Roseli et al. Inventário de Avaliaçấo Pediátrica de Incapacidade (PEDI): aplicabilidade no diagnóstico de transtorno invasivo do desenvolvimento e retardo mental. Med. reabil; v. 29, n. 1, 2010, p. 09-12.

PEREIRA, Amanda Morão et al. Avaliação da memória em crianças e adolescentes com capacidade intelectual limítrofe e deficiência intelectual leve. Rev. psicopedag., São Paulo, v. 32, n. 99, p. 302-313, 2015. Disponível em: $<$ http://pepsic.bvsalud.org/scielo.php?script=sci_arttext\&pid=S0103-84862015000300004\&lng=pt\&nrm=iso>. Acesso em: 07 nov. 2017.

PRIMI, R. Inteligência: avanços nos Modelos teóricos e nos Instrumentos de Medida. Avaliação Psicológica (online), 2003, p.67-77.

SILVA, M. C. V. M. História dos testes psicológicos. São Paulo: Vetor, 1 ed., 2011, 122p.

SOUZA, Fernanda Santos; BATISTA, Cecília Guarnieri. Indicadores de Desenvolvimento em Crianças e Adolescentes com QI Igual ou Inferior a 70. Revista brasileira de educaçáo especial, Marília, v. 22, n. 4, p. 493-510, 2016. Disponível em: <http://www.scielo.br/scielo.php?script=sci_arttext\&pi$\mathrm{d}=$ S1413-65382016000400493\&lng=en\&nrm=iso >. Acesso em: 24 out. 2017.

STELMACHUK, A.C.L.; HAYASHI, M.C.P. Análise bibliométrica sobre avaliação de pessoas com deficiência intelectual para ingresso em serviços de Educação Especial. REICE - Revista Iberoamericana sobre Calidad, Eficacia y Cambio en Educación, v.13, n.2, p.27-49, 2015. Disponível em: <http://www.rinace.net/reice/ numeros/arts/vol13num2/art2.pdf>. Acesso em: 17 nov. 2017.

VELTRONE, Aline Aparecida; MENDES, Enicéia Gonçalves. Descrição das propostas do Ministério da Educação na avaliação da deficiência intelectual. Paidéia, Ribeirão Preto, v. 21, n. 50, p. 413-421, Dez. 2011. Disponível em: <http://www.scielo.br/scielo.php?script=sci_arttext\&pid=S0103863X2011000300014\&ln$\mathrm{g}=\mathrm{en} \& \mathrm{nrm}=\mathrm{iso}>$. Acesso em: 02 Mar. 2017.

\section{Notas}

${ }^{1}$ Público definido de acordo com a Lei de Diretrizes e Bases da Educaçăo, Lei 9394 de 20 de dezembro de 1996, atualizada pela Lei n ${ }^{\circ} 12.796$ de 04 de abril de 2013.

\section{Correspondência}

Érika Rímoli Mota da Silva- Universidade Federal de São Carlos. Rodovia Washington Luís, s/n, São Carlos - SP. CEP: 13565-905. São Carlos, São Paulo, Brasil.

E-mail: rimolierika@hotmail.com - mariadapiedadecostac@gmail.com

Recebido em 23 de março de 2018

Aprovado em 18 de maio de 2018 


\section{(c) (1) () $(9)$}

This work is licensed under a Creative Commons Attribution-NonCommercial 4.0 International (CC BY-NC 4.0) 